\title{
A influência de um programa de iniciação esportiva no desempenho motor e na rotina de atividades de crianças
}

http://dx.doi.org/10.11606/1807-5509201900040569

\begin{tabular}{|c|c|}
\hline $\begin{array}{l}\text { Luciana BRAUNER } \\
\text { Nadia Cristina VALENTINI* } \\
\text { Mariele Santayana de SOUZA* } \\
\text { Larissa Wagner ZANELLA* } \\
\text { Adriana BERLEZE* }\end{array}$ & $\begin{array}{l}\text { 'Escola de Educação } \\
\text { Fisica, Fisioterapia e } \\
\text { Dança, Universidade } \\
\text { Federal do Rio Grande } \\
\text { do Sul, Porto Alegre, } \\
\text { RS, Brasil. }\end{array}$ \\
\hline
\end{tabular}

\section{Resumo}

As oportunidades disponibilizadas para criança em diferentes contextos de desenvolvimento possuem papel fundamental no desfecho motor bem como nos hábitos de vida da criança. Uma base motora diversificada é importante para que a criança possa se inserir com sucesso em atividades esportivas ao longo da adolescência. 0 objetivo deste estudo foi investigar o efeito da inserção de um programa de iniciação esportiva sobre o desempenho motor e na rotina de atividades infantis. 0 Test of Gross Motor Development-Second Edition e um questionário adaptado sobre rotina de atividades na infância foram utilizados no presente estudo. As crianças foram pareadas e distribuidas em grupos controle e interventivo. 0 grupo interventivo participou de um programa de iniciação esportiva, com duração de 35 semanas e 56 dias de aulas. As crianças do grupo interventivo frequentavam o programa duas vezes por semana e as aulas eram implementadas com o clima de motivação para a maestria. As crianças do grupo controle participaram de aulas regulares de educação física duas vezes por semana. Os resultados indicaram: (1) mudanças positivas e significativas do pré- para o pós-intervenção no quociente motor, nas habilidades locomotoras e de controle de objeto no grupo de crianças que participou no programa de intervenção; (2) escores motores superiores no pós-teste para o grupo interventivo; (3) mudanças positivas na rotina de atividade diárias do grupo interventivo; e (4) mudanças negativas na rotina de atividade diárias no grupo controle. A participação em programas esportivos resulta em aumento da proficiência motora e rotinas mais voltadas para o movimento em crianças.

Palavras-Chave: Estudos de Intervenção; Desenvolvimento Infantil; Programas Compensatórios; Criança; Desempenho Motor.

\section{Introdução}

A infância é um período em que as crianças estão envolvidas na exploraçáo e descoberta de movimentos fundamentais ${ }^{1,2}$ os quais são como blocos críticos na construção de habilidades especializadas utilizadas em esportes ${ }^{2,3}$. O desenvolvimento de uma base motora fundamental sólida e diversificada, é essencial para a criança adaptar-se as mais variadas demandas de movimento ${ }^{1}$ que ocorrerão ao longo da adolescência. Entretanto, nem todas as crianças atingem níveis adequados de proficiência motora $^{4-8}$ que permitam o engajamento no esporte. Diferentes oportunidades nos contextos em que a criança está inserida resultarão em trajetória e ritmo distinto de desenvolvimento. A importância do contexto para o desenvolvimento deve ser compreendida não apenas no ambiente em que a criança vive, mas estendendo-se a contextos mais amplos que englobam características culturais, estilos de vida e de organizaçáo social ${ }^{9,10}$, como por exemplo da família. Nos diferentes contextos o indivíduo deve ser entendido como sujeito ativo e passivo; a criança é modificada pelos ambientes, os quais de alguma forma faz parte, mas também os modifica ${ }^{11}$. Consequentemente, modificaçóes 
no comportamento da criança podem repercutir em alterações nas relações familiares e ou escolares que a mesma estabelece. Em contrapartida, o contexto imediato, como o lar, a escola ou o bairro, bem como, as influências mais distantes como instituiçóes sociais ou valores culturais atingem a criança em desenvolvimento ${ }^{12}$ potencializando ou não a aquisiçáo de novos comportamentos.

Compreender as interações entre a criança em desenvolvimento e os contextos em que ela náo participa ativamente mas que de alguma forma afetam seu desenvolvimento (ex: espaços públicos disponíveis para o brincar na infância $)^{12}$ é essencial para a prática pedagógica, uma vez que professores podem promover o envolvimento de pais e crianças em atividades motoras amplas que envolvam jogos e brincadeiras fora do contexto e turno escolar. Ainda mais, compreender se a atividade motora ocorre de forma limitada ou inexiste para além da escola pode auxiliar o professor a entender o desfecho de desenvolvimento de diferentes crianças. O relacionamento da criança, fora do contexto escolar, muitas vezes esta limitado os diferentes adultos que pertencem a estes contextos, esses adultos determinam em grande parte as oportunidades de aprender desta criança e influenciam consequentemente seu desenvolvimento. Por exemplo, pais, professores e amigos propiciam suporte social que exercem níveis variados de influência sobre o engajamento em diversas atividades motoras ${ }^{13}$.

Esta infância da família é a força socializante mais importante para a maioria das crianças ${ }^{12}$, sendo também o maior e mais precoce determinante de suas escolhas motoras e do sucesso em relação a elas $^{14}$, influenciando em grande magnitude as suas atitudes e expectativas ${ }^{15}$. A influência da família se dá inclusive na participação esportiva e na escolha por atividades mais ativas ou sedentárias. Por exemplo, níveis de atividade física de préescolares são influenciados positivamente pela prática de atividades física da mãe, a escolaridade e o status profissional mais elevados da mãe e do pai respectivamente ${ }^{16}$, bem como a profissão dos pais ${ }^{6}$. Uma vez que a estrutura familiar repercute diretamente na rotinas das crianças $^{17}$ consequentemente mudanças de hábitos familiares decorrentes da modernização da sociedade e ou da diminuição de espaços públicos seguros pode repercutir não necessariamente de forma positiva na rotina infantil.

$\mathrm{O}$ aumento das tecnologias na sociedade moderna resulta em mudanças no estilo de vida familiar e a adoção de hábitos de vida mais sedentários ${ }^{18} \mathrm{com}$ por exemplo, o aumento de horas dispendidos pelas crianças na frente de telas eletrônicas ${ }^{19}$. Paralelamente, as alterações na sociedade promovem estilos de vida que requerem menor esforço físico (ex: dependência do transporte motorizados) conduzindo a redução em atividades mais ativas e ao sedentarismo. Esta situação se agrava ainda mais para meninas, para as quais um menor incentivo à prática de atividades físicas ativas ${ }^{20-24}$ ocorre decorrente de características culturais.

Considerando que atividades realizadas no ambiente familiar e escolar podem afetar a participação fisicamente ativa das crianças nos mais variados contextos, torna-se imprescindível não somente investigar a rotina de atividades de crianças ${ }^{6,14,16-17}$ mas também investigar o impacto de programas de intervenção nos hábitos relacionados à rotina da criança no ambiente familiar. Embora estudos atuais reportem o impacto positivo de programas interventivos com enfoque na prática motora diversificada no desempenho motor de crianças ${ }^{5-7,17-19,25,26} \mathrm{o}$ impacto que estas intervenções causam ou não na vida das crianças ainda não são reportados. Portanto, este estudo avança no conhecimento atual e estabelece como objetivo investigar o efeito da inserção de um programa de iniciação esportiva sobre o desempenho motor e na rotina de atividades infantis.

\section{Método}

\section{Participantes}

Inicialmente, respondendo a anúncios em redes sociais, demonstraram interesse em participar do presente estudo 200 crianças de escolas públicas provenientes de famílias de baixa renda (menos

de um salário mínimo nacional). Para todas as crianças foi oferecido a oportunidade de acesso ao programa de iniciação esportiva (PIE). De acordo com a disponibilidade e desejo dos pais 70 crianças ingressaram no PIE compondo o grupo interventivo (GI) e 70 crianças, cujo os pais não demonstraram 
interesse na participação, compuseram um grupo controle (GC), pareadas com as crianças do GI no sexo, idade e desempenho motor. Das 70 crianças do GI, 11 crianças descontinuaram a participação ao longo da intervenção, sendo seus escores excluídos da análise dos dados assim como seus pares correspondentes no GC $(n=11)$. Portanto, a amostra final deste estudo quase-experimental ${ }^{27}$ foi composta de 28 meninas e 31 meninos no GI (Idade: $\mathrm{M}=7,31$ anos; $\mathrm{DP}=$ 1,12 ) e 30 meninas e 29 meninos no GC (Idade: $\mathrm{M}=$ 7,2 anos; $\mathrm{DP}=1,35$ ). Todo os pais e ou responsáveis legais assinaram o Termo de Consentimento Livre e Esclarecido. A pesquisa foi aprovada pelo comitê de ética em pesquisa da universidade de origem.

\section{Instrumentos}

O Test of Gross Motor Development - second edition $(\text { TGMD-2 })^{28}$, adaptado e validado no Brasil ${ }^{29}$ foi utilizado neste estudo. O TGMD-2 é composto de seis habilidades de locomoção (HL) (corrida, galope, corrida lateral, salto horizontal, salto com um pé, saltito) e seis habilidades de controle de objetos (HCO) (rebater, quicar, receber, chutar, arremessar por cima e rolar uma bola). Escores brutos (zero a 48 pontos) são transformados em escores padrão (1 a 20 pontos) para HL e de HCO. A soma dos escores padráo propicia o quociente motor $(0 \mathrm{a} 150$ pontos). Neste estudo utilizou-se os escores padrão e no quociente motor, por levarem em consideração a idade e o sexo da criança no momento da avaliação motora. Quanto às habilidades motoras separadamente foram utilizados os escores brutos. A objetividade entre avaliadores foi obtida por meio da análise independente entre dois avaliadores treinados. $\mathrm{O}$ coeficiente de correlação intraclasse entre os avaliadores foi elevado (quociente motor $\alpha$ $=0,98$ pré-teste; $\mathrm{e} \alpha=0,99$ pós-teste e escore padrão HL, $\alpha=0,98$ pré-teste e $\alpha=0,99$ pós-teste; escore padrão $\mathrm{CO}, \alpha=0,98$ pré-teste e $\alpha=0,98$ pós-teste).

Um questionário ${ }^{30}$ adaptado $^{31}$ sobre a rotina de atividades infantis foi utilizado no presente estudo. O questionário engloba seis aspectos da rotina de atividades infantis: (1) gestão do tempo infantil; (2) meio de transporte utilizado para ir da casa à escola; (3) espaços destinados às brincadeiras; (4) atividades mais frequentes dentro e fora do lar; (5) inter-relaçóes da criança com outras crianças; e, (6) envolvimento familiar em atividades físicas. $\mathrm{O}$ questionário foi respondido pelos pais ou responsáveis legais das crianças do GI e do GC. Para os participantes que não retornaram o questionário, foram realizadas até seis tentativas de entrega para que o preenchimento e devolução fossem efetuados. Quatro participantes do GI e 5 participantes do GC não responderam ao instrumento no pré-teste e 6 crianças do GI e 5 do GC não retornaram o questionário no pós-teste, sendo os dados dos mesmos excluídos da análise referente ao momento em que não responderam o questionário. Nas comparaçôes intragrupo apenas os dados dos participantes que retornaram o questionário preenchido nos dois momentos avaliativos foram utilizados, sendo excluídos os dados dos participantes que náo realizaram o preenchimento do questionário no pré e/ou no pós-teste. Dessa maneira, para as comparaçóes intergrupos no pré-teste foram utilizados os dados de 55 participantes do GI e 54 participantes do GC. No pós-teste foram utilizados os dados de 53 participantes do GI e 54 participantes do GC. Nas comparaçóes intragrupo foram utilizados os dados de 51 crianças do GI e 51 do GC.

Para o uso dos dados do questionário ${ }^{30}$, as respostas relacionadas às atividades realizadas dentro e fora do lar foram categorizadas e agrupadas tendo em vista que duas questões do instrumento eram abertas, nas quais os responsáveis poderiam citar inúmeras opções de atividades que as crianças realizassem. As atividades realizadas dentro do lar foram agrupadas em: (1) atividades de lazer passivo (assistir à televisão e vídeos, atividades no computador e jogos eletrônicos, ouvir música); (2) atividades cognitivas (leitura, quebra-cabeça, sucata e jogos didáticos, educativos, de tabuleiro e de cartas); (3) atividades de motricidade fina (pintar/desenhar, recortar/colar, tocar um instrumento, brincar com bonecas, bonecos, ursinhos, carrinhos, brinquedos de encaixar/montar, bolinha de gude e massinha de modelar); (4) atividades de imitação de tarefas (brincar de casinha, de escola, de ir ao banco e de reproduzir as tarefas de casa) e (5) tarefas de casa. As atividades realizadas fora do lar foram agrupadas em: (1) atividades predominantemente locomotoras (corridas, rodas e cirandas, danças, pular corda, andar de bicicleta, brincadeiras de esconde-esconde, amarelinha, capoeira e subir em árvores) e (2) atividades predominantemente manipulativas (jogos com bola, jogo de taco e pipa).

O controle da variável interveniente, as atividades físicas praticadas pelas crianças em outros programas esportivos durante o período da intervenção, foi realizado por meio de um questionário elaborado 
pelas pesquisadoras e enviado aos pais/responsáveis legais pelos alunos. Questōes referentes a prática de atividades físicas sistemáticas durante o ano de realização da pesquisa e das atividades praticadas na escola compuseram este instrumento.

\section{Implementação do Programa de Iniciação Esportiva}

O PIE teve duração de 35 semanas (abril a novembro) com duas semanas de férias em julho, seguido por mais duas semanas de suspensão das aulas em função da pandemia da Gripe H1N1, totalizando 56 dias de aulas/2 vezes por semana. Durante a realização do estudo muitos dias chuvosos ocorreram, por esse motivo muitas faltas eram identificadas nesses dias justificadas pela dificuldade no transporte até o PIE. Considerando os contratempos citados, a frequência média das crianças foi de $66,44 \%$ considerando os dias de chuva e de $79,45 \%$ desconsiderando os dias de chuva.

As aulas do PIE eram oferecidas nos turnos da manhã ou tarde, com grupos organizados conforme a idade das crianças (GI turma de 5 a 7 anos e GI turma de 8 e 9 anos). O clima de motivação para a maestria foi implementado no presente estudo devido a metodologia inclusiva de crianças na qual a individualidade e ritmo de cada criança nas atividades é respeitado. Este clima promove a autonomia no processo ensino-aprendizagem através do envolvimento ativo das crianças nesse processo. Incorporou-se aos pressupostos do clima de motivação para a maestria os pilares da educação proposto no Programa das Nações Unidas, sendo eles: aprender a ser, aprender a conhecer, aprender a conviver e aprender a fazer tendo o esporte como eixo articulador das ações realizadas voltados para o desenvolvimento das potencialidades motoras, cognitivas, afetivas e sociai ${ }^{32}$ das crianças. A prática de habilidades motoras fundamentais, de jogos pré- esportivos, e dos fundamentos básicos de diferentes esportes (voleibol, futebol, tênis, artes marciais, handebol e basquetebol), bem como jogos esportivos adaptados, foram propiciados as crianças ao longo de aproximadamente 8 meses de prática.

As aulas foram organizadas seguindo os pressupostos teóricos do clima de motivação para a maestria com o uso da estrutura TARGET (Tarefa, Autoridade, Reconhecimento, Grupo, Estratégias de Avaliação e Tempo) $)^{33-35}$ adaptada ao contexto de iniciação esportiva ${ }^{36}$. $\mathrm{Na}$ dimensão tarefa, foram oferecidas atividades motoras variadas e com diferentes níveis de desafio. Estas atividades motoras dispostas em diferentes dinâmicas de estações lúdicas para repetição do movimento e práticas em duplas e pequenos grupos continham os fundamentos básicos dos esportes trabalhados em cada mês. Na dimensão reconhecimento foram propiciados feedbacks de desempenho constantes para cada criança individualmente e para o grupo. $\mathrm{Na}$ dimensão grupo as práticas foram organizadas em pequenos grupos e duplas com crianças com características diferentes (ex.: sexo e níveis de habilidades). $\mathrm{Na}$ dimensão da avaliação as crianças foram avaliadas constantemente em aspectos referentes ao processo e produto da aprendizagem, bem como participaram ativamente das avaliações (ex.: auto avaliaçõos). O tempo de prática em cada tarefa motora foi organizado de acordo com a complexidade da própria tarefa.

\section{Grupo Controle}

As crianças do GC participaram de aulas regulares de Educação Física na escola à paralelo ao período da intervenção na iniciação esportiva do GI. As atividades motoras realizadas nas aulas de educação eram de caráter lúdico e de motricidade ampla, envolviam cantigas de roda, jogos de bola de livre escolha, estafetas e jogos esportivos variados. A instrução para as tarefas eram limitadas a organização do grupo para as praticas com somente e raramente feedbacks motivacionais sendo ministrados. $\mathrm{O}$ foco das professoras eram o controle comportamental das crianças e evitar brigas e indisposiçôes entre alunos. Alguns alunos não participavam das atividades, o que era muitas vezes permitido pelas professoras.

\section{Análise Estatística}

As crianças dos dois grupos foram avaliadas no momento pré e pós- intervenção. General Linear Model com medidas repetidas no fator tempo, ANOVAS e testes post hoc foram conduzidos para avaliar os efeitos da intervenção no desempenho motor dos participantes. Wilks' Lambda $(\Lambda)$ foi adotado como critério das interaçōes. Testes post hoc no fator tempo e grupo foram reportados sempre que a interação foi significativa. Quanto às comparaçōes em cada habilidade motora ANOVA One-Way e test-t pareados foram utilizados.

Com relação as rotinas diárias, o tempo para brincar, assistir à televisão ou vídeos e utilizar 
o computador ou jogos eletrônicos foi descrito através de mediana e amplitude interquartílicas devido à assimetria da distribuição e as demais variáveis (categóricas) foram descritas através de frequências absolutas e relativas. Para comparar o tempo para brincar entre os grupos, em horas, foi utilizado o teste de Mann-Whitney. Para a comparação das variáveis categóricas entre os grupos foram utilizados o teste qui-quadrado de Pearson ou o teste exato de Fisher. Para avaliar as mudanças do pré para o pós-teste nas variáveis de rotina em cada grupo, foi aplicado o teste quiquadrado de McNemar, exceto para o tempo para brincar, que foi avaliado pelo teste de Wilcoxon. Nas comparações entre os sexos foram mantidas as variáveis com no mínimo 10 crianças para que fosse possível avaliar estatisticamente as comparações. Nestas relações foram aplicados os mesmos testes descritos anteriormente. O nível de significância estatística considerado foi de 5\% ( $\leq \leq 0,05)$.

\section{Resultados}

O controle da variável interveniente por meio de questionário respondido pelos pais evidenciou que nenhuma criança tinha experiência prévia esportiva e que ao longo da intervenção também não se engajaram em outros programas esportivos, compensatórios e ou recreativos formais.

\section{Desempenho motor}

Os resultados evidenciaram uma interação significativa entre Grupo X Tempo para o quociente motor $(\Lambda=0,85, \mathrm{~F}(1,116)=20,44, \mathrm{p}<0,001$, $\left.\eta^{2}=0,15\right)$. O tamanho do efeito associado à interação evidencia que $15 \%$ da variabilidade no DM pode ser atribuída ao impacto das experiências vivenciadas ao longo da intervenção. Os efeitos do tempo $\left(\Lambda=0,901, \mathrm{~F}(1,116)=12,78, \mathrm{p}=0,001, \eta^{2}=0,09\right)$ e grupo $\left(F(1,116)=6,34, p=0,013, \eta^{2}=0,52\right)$ foram significantes. Testes post hoc evidenciaram que no pré-teste o DM foi semelhante entre os grupos ( $\mathrm{p}=0,705)$; e no pós-teste GI apresentou desempenho superior ao GC $(\mathrm{p}<0,001)$. Mudanças significativas e positivas foram observadas para o GI do pré-teste para o pós-teste $(\mathrm{p}<0,001)$ enquanto que para GC mudanças significativas $(\mathrm{p}=0,389)$ não foram observadas (FIGURA 1).

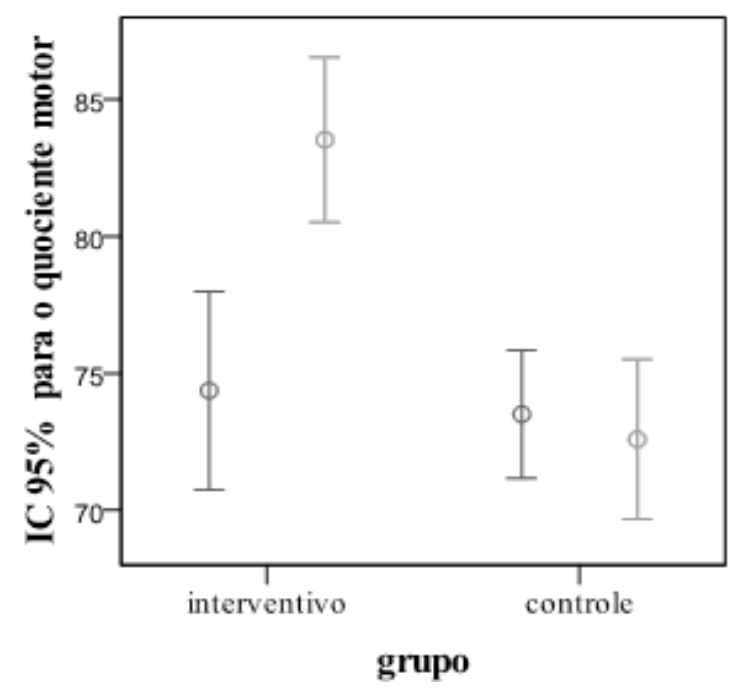

I pré-teste

I pós-teste

FIGURA 1 - Quociente motor dos grupos interventivo e controle no pré-teste e pós-teste.

Para as HL os resultados evidenciaram uma relação significativa entre Grupo X Tempo $(\Lambda=0,96$, $\left.\mathrm{F}(1,116)=5,37, \mathrm{p}=0,022, \eta^{2}=0,04\right)$. O tamanho do efeito associado à interaçáo evidencia que $4,4 \%$ da variabilidade no DM nas HL pode ser atribuída ao impacto das experiências vivenciadas ao longo do período interventivo. Os efeitos do tempo $\left(\Lambda=0,93, \mathrm{~F}(1,116)=8,96, \mathrm{p}=0,003, \eta^{2}=0,07\right)$ e no grupo $\left(\mathrm{F}(1,116)=8,13, \mathrm{p}=0,005, \eta^{2}=0,06\right)$ também foram significantes. Testes post hoc evidenciaram 
que os grupos eram semelhantes nos desempenhos das HL no pré-teste ( $\mathrm{p}=0,184)$; entretanto, no pósteste o GI apresentou desempenho nas HL superior $(<0,001)$. As comparaçóes referentes as habilidades demonstraram que no pós-teste as crianças do GI apresentam escores mais elevados especificamente nas habilidades de corrida $(\mathrm{p}=0,001)$, galope $(\mathrm{p}=0,005)$, salto com um pé $(\mathrm{p}=0,040)$, salto horizontal $(\mathrm{p}=0,002)$ e corrida lateral $(\mathrm{p}=0,006)$.
Em relação ao fator tempo, verificou-se mudanças positivas e significativas do pré-teste para o pós-teste no GI $(\mathrm{p}=0,001)$; especificamente em todas as habilidades locomotoras (corrida: $\mathrm{p}<0,001$; galope: $\mathrm{p}<0,001$; salto com um pé: $\mathrm{p}<0,001$; salto sobre o mesmo pé: $p=0,001$; salto horizontal: $p=0,042$; corrida lateral: $p=0,021)$. Não foram observadas para o GC mudanças significativas $(\mathrm{p}=0,586)$ nas HL do pré-teste para o pós-teste (FIGURA 2).
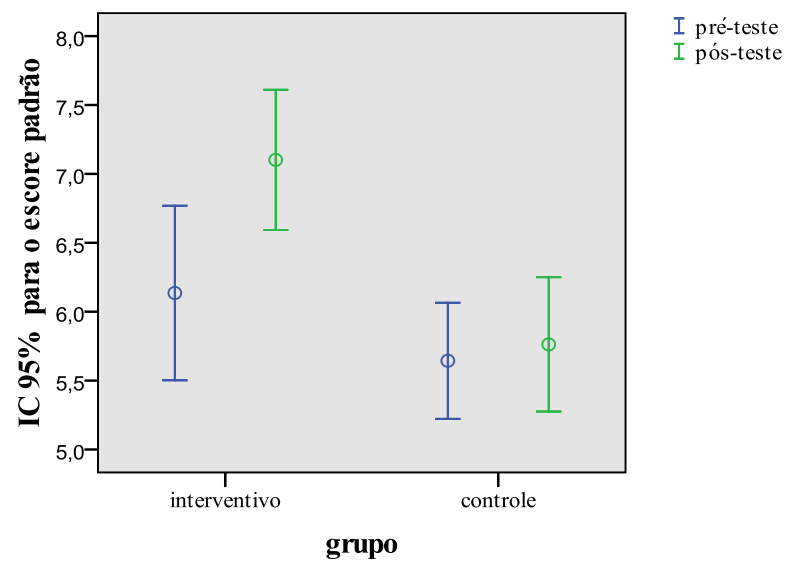

FIGURA 2 -Desempenho motor dos grupos interventivo e controle nas habilidades delocomoção no pré-teste e pós-teste

Para as HCO, os resultados evidenciaram interação significativa entre Grupo X Tempo $(\Lambda=0,79$, $\left.\mathrm{F}(1,116)=30,46, \mathrm{p}<0,001, \eta^{2}=0,20\right)$. O tamanho do efeito associado à interação evidencia que $20,8 \%$ da variabilidade no DM nas habilidades $\mathrm{HCO}$ pode ser atribuída ao impacto das experiências vivenciadas ao longo do período interventivo. Os efeitos do tempo $\left(\Lambda=0,89, \mathrm{~F}(1,116)=13,72, \mathrm{p}<0,001, \eta^{2}=0,1\right)$ e do grupo $\left(F(1,116)=6,15, p<0,015, \eta^{2}=0,05\right)$ também foram significantes. Testes post hoc revelam que os grupos eram semelhantes no pré-teste $(\mathrm{p}=0,581)$ entretanto no pós-teste o GI demonstrou desempenho superior ao $\mathrm{GC}(\mathrm{p}<0,001)$. As comparaçóes referentes as habilidades demonstraram que no pós-teste as crianças do GI apresentam escores mais elevados especificamente nas habilidades de rebater $(\mathrm{p}<0,001)$, quicar $(\mathrm{p}<0,001)$, arremessar $(\mathrm{p}=0,009)$ e rolar a bola $(p=0,002)$. Em relação ao tempo, mudanças significativas e positivas foram observadas para o GI do pré para o pós-teste $(\mathrm{p}<0,001)$; em cinco das seis $\mathrm{HCO}$ (rebater: $\mathrm{p}<0,001$; quicar: $\mathrm{p}<0,001$; receber: $\mathrm{p}=0,172$; chutar: $p<0,001$; arremessar: $p<0,001$; rolar a bola: $\mathrm{p}<0,001)$ à exceção do receber. Não foram observadas para o GC mudanças significativas ( $\mathrm{p}=0,483)$ nas $\mathrm{HCO}$ do pré-teste para o pós-teste (FIGURA 3).

Quanto ao sexo, foi observada interação significativa entre Grupo X Tempo X sexo no quociente motor $(\Lambda=0,77, \mathrm{~F}(3,114)=10,92, \mathrm{p}<0,001$, $\left.\eta^{2}=0,22\right)$; para HL e HCO interaçóes significativas não foram encontradas. Para investigar os resultados da única interaçấo significativa no quociente motor testes de continuidade foram conduzidos. No fator grupo os testes de continuidade evidenciaram desempenho semelhante do GI no pré-teste (pré: $\mathrm{t}(57)=0,294, \mathrm{p}=0,770)$ e no pós-teste $(\mathrm{t}(57)=0,217$, $\mathrm{p}=0,829$ ) entre meninos (pré: $\mathrm{M}=74,90, \mathrm{DP}=13,75$; pós: $\mathrm{M}=83,20, \mathrm{DP}=11,54$ ) e meninas (pré: $\mathrm{M}=73,83$, $\mathrm{DP}=14,25$; pós: $\mathrm{M}=83,86, \mathrm{DP}=11,84)$. Entretanto para o GC no pré-teste $\mathrm{t}(57)=2,370, \mathrm{p}=0,021)$ e no pós-teste $(\mathrm{t}(57)=0,2634, \mathrm{p}=0,011)$ meninos (pré: $\mathrm{M}=76,21, \mathrm{DP}=8,09$; pós: $\mathrm{M}=76,31, \mathrm{DP}=10,76$ ) demonstraram escores de desempenho motor mais elevados do que meninas (pré: $M=70,90$, $\mathrm{DP}=9,05$; pós: $\mathrm{M}=69,00, \mathrm{DP}=10,55)$. No fator tempo, mudanças significativas do pré para o pós intervenção somente foram observadas para o GI para meninas $(\mathrm{p}=0,001)$ e meninos $(\mathrm{p}<0,001)$; no GC mudanças significativas não foram observadas (meninos: $\mathrm{p}=0,950)$; meninas: $\mathrm{p}=0,164$ ). Portanto, para o GI o impacto foi semelhante para meninos e meninas ao longo da intervenção, no GC os meninos apresentaram maiores escores que meninas e não foram observadas mudanças nesses escores ao longo da intervenção. 


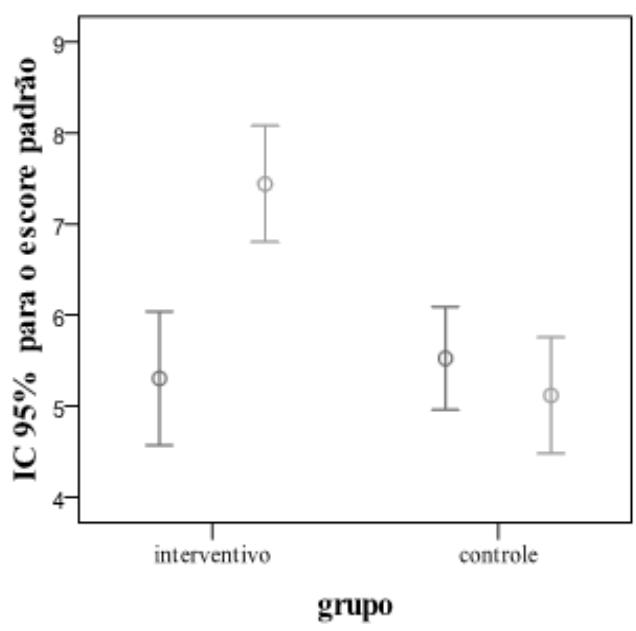

FIGURA 3 -Desempenho motor dos grupos interventivo e controle nas habilidades de controle de objeto no pré-teste e pós-teste

\section{Rotina de atividades infantis}

\section{Gestáo do tempo infantil}

Foram avaliados o turno em que a criança frequenta a escola e o tempo livre que ela dispunha diariamente para brincar. Não foi verificada diferença estatística entre os grupos em relação ao turno de permanência na escola no pré-teste $(\mathrm{p}=0,459)$ e no pós-teste $(\mathrm{p}=0,459)$ ou mudanças ao longo do tempo, tendo em vista que nenhum participante mudou de turno na escola. Aproximadamente metade das crianças do GI (50\%) e do GC (59\%) frequentavam a escola no turno da tarde. Em relação a comparação entre os turnos, não houve diferenças entre crianças que estudavam no turno da manhã e da tarde.

A mediana do tempo livre que os participantes dispunham para brincar foi de 3 horas no pré e também no pós-teste. Não foram verificadas diferenças significativas entre os grupos em nenhum dos momentos avaliativos (pré-teste: GI x GC, p=0,206; pós-teste: GI x GC, p=0,860), assim como não foram verificadas mudanças do pré para o pós-teste (GI: $p=0,735 ; \mathrm{GC}: \mathrm{p}=0,085)$. Não foram verificadas diferenças significativas entre os sexos no que diz respeito à gestão do tempo infantil, quer seja para o turno de permanência na escola ou para o tempo livre disponível para brincar relatado pelos pais ou responsáveis pelos participantes.

\section{Deslocamento no trajeto para a escola}

A maioria dos participantes do GI (pré: 59\%; pós: $53 \%$ ) e GC (pré: 78\%; pós: 72\%) deslocavase através de meios de transporte não motorizados nesse trajeto (a pé ou de bicicleta, por exemplo), não havendo diferença significativa entre os grupos (pré: $\mathrm{p}=0,128$; pós: $\mathrm{p}=0,158$ ). As mudanças ao longo do tempo dentro de cada grupo não foram significativas (GI: $p=0,223$; GC: $p=0,572$ ). O tipo de transporte utilizado para o deslocamento casaescola foi semelhante entre os sexos, tanto para o GI quanto para o GC.

\section{Espaços destinados para as brincadeiras}

No pré-teste e no pós teste não foram encontradas diferenças significativas entre os grupos para crianças que brincavam dentro de casa/ apartamento (pré: $\mathrm{p}=0,901$; pós: $\mathrm{p}=0,643$ ), dentro de casa/apartamento e no pátio (pré: $\mathrm{p}=0,910$; pós: $\mathrm{p}=0,820$ ), na rua (pré: $\mathrm{p}=0,741$; pós: $\mathrm{p}=0,828$ ) e em parques (pré: $\mathrm{p}=0,947$; pós: $\mathrm{p}=0,837$ ).

Ao comparar do pré-teste para o pós-teste também não foram encontradas diferenças significativas ao comprar as crianças intragrupo que brincavam dentro de casa/apartamento (GI: $p=1,000$; GC: $p=1,000)$, dentro de casa/ apartamento e no pátio (GI: $p=1,00, \mathrm{GC}$ : $p=1,000)$, na rua (GI: $p=0,754$; GC: $p=1,000)$ e em parques (GI: $p=0,727$; $G C: p=1,000)$. A TABELA 1 apresenta o número de crianças que brincavam em cada local e por grupo. A maioria das crianças investigadas não tem por hábito brincar na rua ou em parques. Apenas 34\% dos participantes do grupo interventivo e $31 \%$ do controle relataram brincar em parques, sendo ainda menor o percentual de crianças que brinca na rua. 
* Valores obtidos nas comparações intergrupos através do teste exato de Fisher:;

** Valores obtidos nas comparações intragupo através do teste qui-quadrado de McNemar.
${ }_{1}$ Um participante do grupo controle não respondeu a essa questão no pré-teste;

* Valores obtidos nas comparações intergrupos através do teste de qui-quadrado de

Pearson;

** Valores obtidos nas comparações intragupo através do teste qui-quadrado de McNemar

TABELA 1 -Locais nos quais os participantes realizam suas brincadeiras

\begin{tabular}{|c|c|c|c|c|c|c|c|c|c|c|c|c|}
\hline \multirow[b]{4}{*}{ Teste } & \multicolumn{12}{|c|}{ Locais para Brincar: $\mathbf{n}(\%)$} \\
\hline & \multicolumn{6}{|c|}{ Dentro de casa } & \multicolumn{6}{|c|}{ Espaços Abertos } \\
\hline & \multicolumn{3}{|c|}{ Apartamento } & \multicolumn{3}{|c|}{ Apartamento e Pátio } & \multicolumn{3}{|c|}{ Na Rua } & \multicolumn{3}{|c|}{ Em parques } \\
\hline & GI & GC & $\mathbf{p}^{*}$ & GI & GC & $\mathbf{p}^{*}$ & GI & GC & $\mathbf{p}^{*}$ & GI & GC & $\mathbf{p}^{*}$ \\
\hline pré & $13(24)$ & $12(22)$ & 0,901 & $42(76)$ & $42(78)$ & 0,910 & $13(24)$ & $14(26)$ & 0,741 & $19(34)$ & $17(31)$ & 0,947 \\
\hline pós & $12(23)$ & $11(20)$ & 0,643 & $41(77)$ & $43(80)$ & 0,820 & $15(28)$ & $14(26)$ & 0,828 & $18(34)$ & $17(31)$ & 0,837 \\
\hline $\mathbf{p}^{* *}$ & 1,000 & 1,000 & - & 1,000 & 1,000 & - & 0,754 & 1,000 & - & 0,727 & 1,000 & - \\
\hline
\end{tabular}

\section{Inter-relaçöes da criança com outras crianças}

Não foram verificadas diferenças significativas entre os grupos quanto ao número de crianças que brincam sozinhas (pré: $p=0,495$; pós: $p=0,495$ ), somente com amigos do bairro (pré: $\mathrm{p}=0,776$; pós: $\mathrm{p}=0,437$ ), somente com amigos da escola (pré: $\mathrm{p}=0,366$; pós: $\mathrm{p}=1,000)$ ou que brincam com amigos do bairro e da escola (pré: $\mathrm{p}=0,556$; pós: $\mathrm{p}=0,520$ ). Foi verificado incremento significativo do pré para o pós-teste no número de participantes que brincavam com amigos do bairro e da escola apenas no GI ( $\mathrm{p}=0,021)$; no GC não foram encontradas diferenças significativas $(\mathrm{p}=0,791)$. Não foram identificadas mudanças significativas do pré para o pós-teste em nenhum dos grupos no número de participantes que brincavam sozinhos (GI: $\mathrm{p}=1,000$; GC: $\mathrm{p}=1,000$ ), com amigos do bairro (GI: $\mathrm{p}=0,219$; GC: $\mathrm{p}=0,453$ ) ou com amigos da escola (GI: $p=0,125$; GC: $\mathrm{p}=1,000)$. Os resultados foram semelhantes entre os sexos em todas as possibilidades de resposta dessa questão. Apenas um participante do grupo controle no pré-teste e dois no pós-teste relataram brincar sozinhos. As frequências de crianças que brincavam com crianças do bairro, da escola ou o bairro e da escola são apresentados na TABELA 2.

TABELA 2 -Relacionamento dos participantes com os pares nas brincadeiras

\begin{tabular}{ccccccccccccccc}
\hline \multicolumn{1}{c}{} & \multicolumn{1}{c}{ Inter-relaçóes da criança com outras crianças: n(\%) } \\
\hline & \multicolumn{1}{c}{ Sozinho } & \multicolumn{3}{c}{ Bairro } & \multicolumn{3}{c}{ Escola } & \multicolumn{3}{c}{ Bairro e Escola } \\
\hline Teste & GI & GC1 & p & GI & GC1 & p & GI & GC1 & p & GI & GC1 & p \\
\hline pré & $00(0)$ & $01(2)$ & 0,495 & $08(15)$ & $06(11)$ & 0,776 & $14(25)$ & $10(18)$ & 0,366 & $33(60)$ & $33(67)$ & 0,556 \\
pós & $00(0)$ & $02(4)$ & 0,495 & $02(4)$ & $05(9)$ & 0,437 & $10(19)$ & $10(19)$ & 1,000 & $41(77)$ & $37(68)$ & 0,520 \\
p $^{* *}$ & 1,000 & 1,000 & & 0,219 & 0,453 & & 0,125 & 1,000 & & 0,021 & 0,791 & \\
\hline
\end{tabular}

\section{Atividades mais praticadas dentro lar}

Nessa questão, os participantes relataram a participação em atividades com predomínio de movimentação restrita e de caráter passivo. Não foram encontradas diferenças significativas no préteste e no pós-teste entre os GI e GC nas atividades praticadas no lar nas categorias: cognitivas (pré: $\mathrm{p}=0,297$; pós: $=0,385$ ), lazer passivo (pré: $\mathrm{p}=0,243$; pós: $\mathrm{p}=0,495$ ) e motricidade fina (pré: $\mathrm{p}=0,527$; pós:=0,340). Não foram encontradas diferenças significativas do pré-teste para o pós-teste nos grupos: cognitivas (GI: $p=1,000$; GC: $p=0,815$ ), lazer passivo (GI: $p=1,000$; GC: $p=1,000)$ e motricidade fina (GI: $\mathrm{p}=0,219$; GC: $\mathrm{p}=0,625)$.

As atividades de lazer passivo são aquelas que um maior número de participantes realizava. Dentre essas atividades, a mais praticada foi assistir à televisão ou vídeo. Apenas um participante (2\%) do GI e sete $(12 \%)$ do GC relataram não realizar essa atividade no pré-teste. No pós-teste, esse número aumentou para quatro participantes (7\%) no GI e se manteve em 7 (12\%) no GC, entretanto as diferenças não foram significativas. A segunda atividade mais realizada dentre as de lazer passivo diferiu entre os grupos. Para o GI, a segunda tarefa realizada pelo maior número de participantes foi a utilização de computador e jogos eletrônicos, estando em terceiro lugar para as crianças do GC. No GI, $61 \%$ dos participantes no pré-teste e $74 \%$ no pós-teste relataram praticar essas atividades. No GC, apenas $48 \%$ dos participantes no pré-teste e $50 \%$ no pós-teste relataram utilizar o computador no seu tempo livre. Apesar do maior número de crianças do GI que realizavam essa atividade, a diferença entre 
os grupos não foi considerada significativa $(\mathrm{p}=0,858$ no pré-teste; $\mathrm{p}=0,399$ no pós-teste).

Não foi verificada mudança significativa $(\mathrm{p}=0,323)$ no tempo despendido na utilização de computadores e jogos eletrônicos do pré para o pós-teste no GI (pré: $\mathrm{MED}=1$ hora, $\mathrm{p} 25=30$ minutos, $\mathrm{p} 75=1$ hora; pós: $\mathrm{MED}=1$ hora, $\mathrm{p} 25=30$ minutos, $\mathrm{p} 75=1$ hora e 20 minutos). No GC, entretanto, o tempo gasto nessa atividade aumentou significativamente $(p=0,046)$ do pré $(\mathrm{MED}=1$ hora, $\mathrm{p} 25=30$ minutos, $\mathrm{p} 75=1$ hora) para o pós-teste $(\mathrm{MED}=1$ hora, p25 $=40$ minutos, $\mathrm{p} 75=2$ horas). $\mathrm{O}$ tempo diário que os participantes permaneciam nessa atividade foi de duas horas no pré-teste (GI: p25=1 hora, p75=3 horas; GC: $\mathrm{p} 25=1$ hora, $\mathrm{p} 75=2,75$ horas) para ambos os grupos $(\mathrm{p}=0,814)$. No pós-teste a mediana do tempo despedido na tarefa de assistir à televisão ou vídeos permaneceu em duas horas para ambos os grupos (GI: p25=1 hora, p75=2 horas; GC: $\mathrm{p} 25=2$ horas, $\mathrm{p} 75=3$ horas), entretanto, nesse momento foi verificada diferença significativa entre os grupos GI e
$\mathrm{GC}(\mathrm{p}=0,012)$. De acordo com os resultados, o grupo GI relatou assistir à televisão ou vídeos por menos tempo que o GC no pós-teste. Apesar dessa diferença significativa entre os grupos GC e GI, não foram verificadas mudanças do pré para o pós-teste em nenhum dos grupos (GI: $p=0,077 ; \mathrm{GC}: \mathrm{p}=0,377$ ). A TABELA 3 apresenta as frequências de crianças que brincavam nas categorias cognitiva, lazer passivo e motricidade fina nos grupos.

Também não foram encontradas diferenças significativas no pré-teste e no pós-teste entre GI e GC nas atividades praticadas no lar nas categorias: imitação de papéis (pré: $\mathrm{p}=0,488$; pós: $=1,000)$ e tarefas de casa (pré: $\mathrm{p}=0,243$; pós: $\mathrm{p}=0,502)$. Não foram encontradas diferenças significativas do pré-teste para o pós-teste nos grupos: imitação de papéis (GI: $\mathrm{p}=0,344$; GC: $\mathrm{p}=1,000)$ e tarefas de casa (GI: $\mathrm{p}=0,210$; GC: $\mathrm{p}=0,581$ ). A TABELA 4 apresenta as frequências de crianças que brincavam nas categorias imitação de papeis e tarefas de casa nos grupos.

TABELA 3 -Atividades praticadas dentro do lar: cognitivas, lazer passivo e motricidade fina.

\begin{tabular}{cccccccccc}
\hline \multicolumn{8}{c}{ Atividades praticadas pela criança dentro do lar: n(\%) } \\
\hline & & Cognitivas & \multicolumn{1}{c}{ Lazer Passivo } & \multicolumn{3}{c}{ Motricidade Fina } \\
\hline Tempo & GI & GC & p & GI & GC & p & GI & GC & p \\
\hline pré & $31(56)$ & $24(45)$ & 0,297 & $55(100)$ & $52(96)$ & 0,243 & $51(93)$ & $48(8)$ & 0,527 \\
pós & $29(55)$ & $24(44)$ & 0,385 & $53(100)$ & $52(96)$ & 0,495 & $45(85)$ & $50(93)$ & 0,340 \\
p $^{* *}$ & 1,000 & 0,815 & - & 1,000 & 1,000 & - & 0,219 & 0,625 & - \\
\hline
\end{tabular}

TABELA 4 -Atividades praticadas dentro do lar: imitação de papeis e tarefas de casa.

\begin{tabular}{ccccccc}
\hline \multicolumn{5}{c}{ Atividades praticadas pela criança dentro do lar: n(\%) } \\
\hline \multicolumn{5}{c}{ Imitaçáo de Papéis } & Tarefas de casa \\
\hline Tempo & GI & GC & P & GI & GC & p \\
\hline pré & $10(18)$ & $06(11)$ & 0,488 & $18(33)$ & $23(43)$ & 0,243 \\
pós & $06(11)$ & $07(13)$ & 1,000 & $23(43)$ & $19(35)$ & 0,502 \\
p $^{* *}$ & 0,344 & 1,000 & - & 0,210 & 0,581 & - \\
\hline
\end{tabular}

\section{Atividades mais praticadas fora do lar}

Foram averiguadas também as atividades realizadas pelos participantes fora do lar, com predominância de ampla movimentação. Não foram encontradas diferenças significativas no pré-teste e pós-teste entre os grupos nas atividades de locomoção (pré: $\mathrm{p}=1,000$; pós: $\mathrm{p}=0,489$ ) e de manipulação (pré: $\mathrm{p}=0,778$; pós: $\mathrm{p}=0,678)$. Também não foram encontradas diferenças significativas nos grupos no momento pré-teste para o momento pós-teste nas atividades de locomoção (GI: $p=1,000 ; G C: p=1,000)$ e de manipulação (GI: $\mathrm{p}=0,267$; GC: $\mathrm{p}=1,000$ ).

As atividades de manipulação fora do lar também foram relatadas por um grande número de participantes. Dentre essas atividades, a realizada pelo maior número de crianças foi pintar/ desenhar, realizada por aproximadamente $75 \%$ dos participantes investigados no pré e também no pós-teste, seguida por brincadeiras com bonecas/
* Valores obtidos nas comparações intergrupos através do teste de qui-quadrado de Pearson;

** Valores obtidos nas comparações intragupo através do teste qui-quadrado de McNemar.

* Valores obtidos nas comparações intergrupos através do teste de qui-quadrado de Pearson;

** Valores obtidos nas comparações intragupo através do teste qui-quadrado de McNemar. 
* Valores obtidos nas comparações intergrupos através do teste de qui-quadrado de Pearson;

** Valores obtidos nas comparações intragupo através do teste qui-quadrado de McNemar. bonecos e ursinhos, realizadas por aproximadamente $58 \%$ dos participantes de ambos os grupos no préteste e $50 \%$ do grupo interventivo e $60 \%$ do grupo controle no pós-teste. As atividades de locomoção foram mais praticadas que as de manipulação. Dentre as atividades predominantemente de locomoção, aquela praticada pelo maior número de participantes foram brincadeiras de corrida, citadas por $84 \%$ das crianças do GI no pré-teste e $70 \%$ no pós-teste, e por $70 \%$ dos participantes do GC no pré-teste e $67 \%$ no pós-teste. A segunda atividade de locomoção mais praticada é andar de bicicleta, sendo realizada por aproximadamente
$60 \%$ dos participantes dos dois grupos no pré e no pós-teste. Dentre as brincadeiras com predomínio de movimentos de manipulação, a mencionada pelo maior número de participantes foram os jogos com bola, tanto no pré-teste (GI: 80\%; GC: $76 \%$ ) quanto no pós-teste (GI: 76\%; GC: 78\%). As demais atividades eram realizadas por no máximo duas crianças de cada grupo no pré ou no pósteste. Meninos e meninas dos grupos interventivo e controle apresentaram resultados semelhantes no pré ou no pós-teste. A TABELA 5 apresenta as frequências de crianças que praticavam cada tipo de atividade em relação aos grupos.

TABELA 5-Atividades mais praticadas pelos participantes fora do lar

\begin{tabular}{ccccccc}
\hline & \multicolumn{5}{c}{ Atividades praticadas fora do lar: $\mathbf{n}(\%)$} \\
\hline Tempo & GI & GC & $\mathbf{p}^{*}$ & GI & GC & p $^{*}$ \\
\hline Pré & $50(91)$ & $49(91)$ & 1,000 & $44(80)$ & $41(76)$ & 0,778 \\
Pós & $48(90)$ & $51(94)$ & 0,489 & $40(76)$ & $42(78)$ & 0,678 \\
p $^{* *}$ & 1,000 & 1,000 & - & 0,267 & 1,000 & - \\
\hline
\end{tabular}

\section{Envolvimento familiar em atividades físicas}

Com relação à prática de atividade física dos familiares dos participantes. Não foram encontradas diferenças significativas entre os grupos no pré-teste ou no pós-teste em relação à prática do pai (pré: $\mathrm{p}=0,244$; pós: $\mathrm{p}=0,906$ ), mãe (pré: $\mathrm{p}=0,246$; pós: $\mathrm{p}=1,000$ ), irmãos (pré: $\mathrm{p}=0,155$; pós: $\mathrm{p}=0,343$ ) e pai e mãe (pré: $\mathrm{p}=0,657$; pós: $\mathrm{p}=0,514)$. Observa-se que no pré-teste pais, mães e irmáos dos participantes dos GI e GC realizavam atividades físicas de forma semelhante.

Ao analisar as mudanças das práticas físicas dos familiares do pré-teste para o pós-teste, no pósteste observam-se mudanças de comportamento dos familiares dos participantes do GI. Foram verificadas mudanças significativas do pré para o pós-teste somente no número de crianças do $\mathrm{GI}$, as quais o pai praticava atividades físicas (GI: $\mathrm{p}=0,021$; GC: $\mathrm{p}=1,00$ ), assim como no número de crianças as quais o pai e a mãe realizavam essas atividades (GI: $p=0,022$; $G C: p=1,000$ ). Em relação a prática de atividades físicas por parte das máes (GI: $\mathrm{p}=0,581$; GC: $\mathrm{p}=0,125)$ e irmãos (GI: $\mathrm{p}=1,000$; GC: $p=0,289)$ não foram encontradas modificaçóes significativas do pré-teste para o pós-teste.

O aumento do número de crianças envolvendo a prática do pai no GI dependeu do sexo. O aumento foi significativo apenas nos meninos (pré: $6(30,0 \%)$ e pós: $12(60,0 \%), \mathrm{p}=0,031)$. Nas meninas o mesmo não ocorreu (pré $8(42,1 \%)$ e pós: $11(57,9 \%), p=0,508)$. Essa foi a única variável da pesquisa com diferença significativa entre os sexos. No envolvimento concomitante de pais e mães não pôde ser observada diferença conforme os sexos tanto no GI (meninos: $p=0,125$; meninas: $\mathrm{p}=0,289)$ quanto no GC (meninos: $\mathrm{p}=0,375$; meninas: $\mathrm{p}=0,500$ ), provavelmente por não depender do sexo da criança.

TABELA 6-Envolvimento familiar na prática de atividades físicas

\begin{tabular}{|c|c|c|c|c|c|c|c|c|c|c|c|c|}
\hline \multirow[b]{3}{*}{ Tempo } & \multicolumn{12}{|c|}{ Envolvimento familiar em atividades físicas: $\mathbf{n}(\%)$} \\
\hline & \multicolumn{3}{|c|}{$\mathrm{Pai}^{1}$} & \multicolumn{3}{|c|}{ Máe $e^{2}$} & \multicolumn{3}{|c|}{ Irmáos ${ }^{3}$} & \multicolumn{3}{|c|}{ Pai e mãe ${ }^{4}$} \\
\hline & GI & GC & $\mathbf{p}^{*}$ & GI & GC & $\mathbf{p}^{*}$ & GI & GC & $\mathbf{p}^{*}$ & GI & GC & $\mathbf{p}^{*}$ \\
\hline \multicolumn{13}{|c|}{ Atividades em Geral } \\
\hline Pré & $19(41)$ & $22(55)$ & 0,244 & $30(58)$ & $33(70)$ & 0,246 & $28(67)$ & $30(83)$ & 0,155 & $16(36)$ & $16(41)$ & 0,657 \\
\hline pós & $26(50)$ & $21(52)$ & 0,906 & $31(59)$ & $28(58)$ & 1,000 & $29(58)$ & $26(70)$ & 0,343 & $21(40)$ & $13(33)$ & 0,514 \\
\hline
\end{tabular}


continuação

\begin{tabular}{|c|c|c|c|c|c|c|c|c|c|c|c|c|}
\hline \multirow[b]{3}{*}{ Tempo } & \multicolumn{12}{|c|}{ Envolvimento familiar em atividades físicas: $\mathrm{n}(\%)$} \\
\hline & \multicolumn{3}{|c|}{ Pai $^{1}$} & \multicolumn{3}{|c|}{ Máe $e^{2}$} & \multicolumn{3}{|c|}{ Irmáos ${ }^{3}$} & \multicolumn{3}{|c|}{ Pai e mãe4 } \\
\hline & GI & GC & $\mathbf{p}^{*}$ & GI & GC & $\mathbf{p}^{*}$ & GI & GC & $\mathbf{p}^{*}$ & GI & GC & $\mathbf{p}^{*}$ \\
\hline \multicolumn{13}{|c|}{ Atividades em Geral } \\
\hline $\mathbf{p}^{* *}$ & 0,021 & 1,000 & - & 0,581 & 0,125 & - & 1,000 & 0,289 & - & 0,022 & 1,000 & - \\
\hline \multicolumn{13}{|c|}{ Todos os dias } \\
\hline pré & $03(7)$ & $04(18)$ & - & $06(12)$ & $08(17)$ & - & $06(14)$ & $10(28)$ & - & - & - & - \\
\hline pós & $02(4)$ & $04(10)$ & - & $06(11)$ & 09(19) & - & $07(14)$ & $10(27)$ & - & - & - & - \\
\hline \multicolumn{13}{|c|}{2 a $3 \times$ semanais } \\
\hline pré & 08(17) & $07(31)$ & - & $17(32)$ & 08(17) & - & $19(46)$ & $17(47)$ & - & - & - & - \\
\hline pós & $15(29)$ & $09(22)$ & - & 19(37) & $07(14)$ & - & $19(38)$ & $14(38)$ & - & - & - & - \\
\hline \multicolumn{13}{|c|}{ Fim de semana } \\
\hline pré & $08(17)$ & $11(50)$ & - & $07(14)$ & $17(36)$ & - & $03(7)$ & $03(8)$ & - & - & - & - \\
\hline pós & $09(17)$ & $08(20)$ & - & $06(11)$ & $12(25)$ & - & $03(6)$ & $02(5)$ & - & - & - & - \\
\hline \multirow{2}{*}{\multicolumn{13}{|c|}{$\begin{array}{l}\text { * Valores obtidos nas comparações intergrupos através do teste de qui-quadrado de Pearson; } \\
\text { ** Valores obtidos nas comparaçôes intragupo através do teste qui-quadrado de McNemar. }\end{array}$}} \\
\hline & & & & & & & & & & & & \\
\hline \multicolumn{13}{|c|}{$\begin{array}{l}\text { Nota: }{ }^{1} \text { Os escores dos participantes que não convivem ou não conhecem seu pai foram excluídos dessa análise; }{ }^{2} \text { Os escores } \\
\text { dos participantes que não convivem ou não conhecem sua mãe foram excluídos dessa análise; }{ }^{3} \text { Os escores dos participantes } \\
\text { que não têm ou não convivem irmãos foram excluídos dessa análise; } 4 \text { Os escores dos participantes que não convivem ou não } \\
\text { conhecem seu pai e/ou mãe foram excluídos dessa análise. }\end{array}$} \\
\hline
\end{tabular}

\section{Discussão}

\section{Desempenho Motor}

Verificou-se no presente estudo o impacto positivo do PIE no desempenho motor dos participantes, similar a resultados prévios de programas com enfoque em habilidades motoras fundamentais ${ }^{5,26,35,37-40}$ e na iniciaçáo esportiva do tênis ${ }^{36}$. O presente estudo entretanto, avança ao propiciar suporte ao clima de motivaçáo para a maestria na iniciação de crianças nos mais variados esportes ao longo de aproximadamente 8 meses. As estratégias alinhadas com o clima motivacional foram eficazes em promover ganhos similares entre meninos e meninas de diferentes idades em todas os parâmetros mensurados. Destaca-se especificamente as mudanças de médias mais elevadas nas $\mathrm{HCO}$ no $\mathrm{GI}$, as quais são mais dependentes de feedback e instrução do professor ${ }^{18,19}$. Uma vez que o enfoque da intervenção era a iniciação esportiva.

Além de instrução adequada, a prática constante, prolongada e apropriada ${ }^{1,18,19,25}$ com diferentes níveis de desenvolvimento ${ }^{35,41}$ dos fundamentos do voleibol, tênis, basquetebol e handebol foram essenciais para as mudanças observadas. O PIE possibilitou que as crianças praticassem as atividades adequando o desempenho às exigências das tarefas quanto à adequação, trajetória, distância, velocidade e características do objeto em movimento, demandas intrínsecas do esporte, as quais repercutiram também nas habilidades mais básicas investigadas no presente estudo. Consequentemente esse estudo evidencia que apesar de as crianças não apresentarem no início do programa níveis proficientes nas habilidades motoras fundamentais, requerimento para a prática eficiente de habilidades esportivas ${ }^{42}$, ao longo do programa estas habilidades foram mudando paralelas à aquisição de habilidades especializadas dos esportes praticados. O PIE foi eficiente em promover o desenvolvimento dos participantes de maneira ampla, em 11 das habilidades motoras fundamentais investigadas, decorrência possível de diversificação de tarefas motora vivenciadas, dos grandes e pequenos jogos, dos jogos pré-desportivos e dos esportes praticados.

Portanto, os pressupostos do contexto motivacional para a maestria, empregados neste programa, mostrou-se eficiente na promoçáo de habilidades motoras fundamentais embora o enfoque fosse de cunho esportivo em um tempo 
relativamente curto. Vários estudos $5,25,26,37-40,43$ sugerem que mesmo em períodos considerados curtos de intervenção (aproximadamente 12 semanas) mudanças significativas no desempenho das habilidades motoras fundamentais podem ser facilmente observadas se práticas adequadas e diversificadas dessas habilidades, forem implementadas. O presente estudo evidencia que as habilidades especializadas de vários esportes repercutem na melhoria de habilidades motoras fundamentais, similar a resultado prévio no tênis ${ }^{36}$. Os resultados permitem inferir que o programa foi eficiente em atender as necessidades educacionais de todas as crianças, proporcionando condições, tarefas e instruçóes adequadas aos diferentes níveis de desempenho, tendo em vista que meninos e meninas de todas as idades se beneficiaram da intervenção.

Os pressupostos do contexto motivacional para a maestria que promovem a autonomia da criança aliados aos pilares da educação do aprender a ser, aprender a conhecer, aprender a conviver e aprender a fazer tendo o esporte como eixo articulador potencializou mudanças motoras em crianças que não possuíam previamente nenhuma prática esportiva e que ao longo do intervenção somente frequentaram o programa investigado. A participação em programas de iniciação esportiva de caráter publico e social se constitui em uma alternativa adequada para crianças com poucas oportunidades de pratica motora para além da escola; tendo em vista que a realidade econômica destas crianças pode ser o fator da falta de oportunidades, de estímulos para a prática e de encorajamento, ou ainda a carência de instrução adequada ${ }^{26,36,38,40,44}$.

\section{Rotina de atividades infantis}

Os resultados indicam que houve aumento do número de crianças do programa esportivo que passaram a brincar mais com outras crianças do bairro ou da escola. Os efeitos da diminuição no número de participantes do programa que brincavam somente com amigos do bairro (pré: $15 \%$, pós: $4 \%$ ) ou somente com amigos do colégio (pré: 25\%, pós: $19 \%$ ) e que passaram a brincar com os pares de outros no pós-teste, indicam que estas crianças passaram a interagir com um número maior de crianças provenientes de sua comunidade não ficando restritas somente aos amigos próximos que já tinham. O maior envolvimento em brincadeiras com os novos amigos da comunidade é relacionado às relações que a criança passa a ter ao conhecer outras crianças no programa de iniciação esportiva aumentando as oportunidades envolveremse em brincadeiras em outros ambientes. $\mathrm{O}$ suporte dos amigos para o maior envolvimento em atividades físicas é essencial ${ }^{45}$. Crianças mais aceitas socialmente ${ }^{46}$ e crianças e adolescentes que recebem mais apoio de pares ${ }^{47}$ envolvem-se mais em atividades físicas. No presente estudo a participação no programa pode ter sido responsável pelas mudanças nas relaçôes entre os participantes, criando novas oportunidades de relacionamentos e a amizade, consequentemente levando-as para outros ambientes além do programa.

Ainda mais, os pais e pais e mães dessas crianças passaram a praticar mais atividades físicas do início ao final do programa de iniciação esportiva. Estudos tem investigado as relações entre os níveis de atividade física de pais e filhos adolescentes com resultados contraditórios. É consenso de que há influência de que quando são analisados ambos os pais. Por exemplo, associações são reportadas entre os níveis e atividade física de lazer conjuntamente do pai e da mãe com os níveis de atividade física dos filhos adolescentes ${ }^{48}$ bem como para crianças e adolescentes ${ }^{49}$, entretanto o envolvimento de ambos pais parece determinante ${ }^{48,49}$ pois o estilo de vida adotado pelas mães independentemente algumas vezes parece não influenciar os hábitos dos meninos ${ }^{49}$.

O presente estudo, similar aos estudos reportado previamente quanto a influencia nos níveis de atividade física ${ }^{48,49}$, ressalta que os hábitos dos pais pode também podem influenciar o desempenho motor das crianças. Poucos estudos ${ }^{6}$ tem investigado esta relação, e, portanto, esta se configura como uma contribuição original do presente estudo. $\mathrm{O}$ maior envolvimento dos pais e pais e mães em atividades físicas pode estar relacionado as mudanças nas brincadeiras das crianças, as quais passam a se envolver em mais atividades com as crianças do bairro e da escola. Ao aumentar os laços de amizade, as crianças possivelmente passaram a brincar mais, o que muitas vezes as leva a deslocarem-se mais na própria comunidade. Consequentemente considerando a idade das crianças, possivelmente os pais e mães das crianças podem ter passado a acompanha-las nas atividades, talvez mudando as atividades físicas praticadas por eles. Essa suposição se dá principalmente ao considerarmos a idade das crianças investigadas, as quais ainda dependem dos responsáveis para realizar as atividades. 
Em relação ao deslocamento para a escola, a maioria das crianças já utilizavam meio de transporte não motorizado antes de iniciarem a participação no PIE e assim se mantiveram ao longo da intervenção. Evidências previas sugerem que a maioria das crianças que residem em regiōes centrais de cidades provenientes de classe média realizam trajetos escolares através de transportes motorizados ${ }^{30,50,51}$, contrariamente no presente estudo esse tipo de transporte era utilizado pela minoria dos participantes do grupo interventivo e do grupo controle. As crianças do presente estudo provem de classes socioeconomicamente mais baixas o que termina por repercutir no deslocamento a pé ou de bicicleta para a escola.

O tipo de transporte utilizado no trajeto de ida e/ou volta da escola tem sido associado aos níveis de atividade física diária de crianças ${ }^{23,52,53}$ com importantes repercussôes para a saúde das mesmas. COOPER et al. ${ }^{23}$ realizaram estudo com 323 participantes dinamarqueses com idade de nove anos e verificaram que as crianças que realizavam esse percurso a pé (24\%) permaneciam mais tempo em atividades físicas de nível moderado ou intenso durante o dia (40 minutos a mais para as meninas e 34 minutos para os meninos) quando comparadas àquelas que realizavam o trajeto de carro $(25 \%)$ ou de ônibus (12\%). Deslocar-se de bicicleta nesse trajeto, que foi o meio utilizado pela maioria dos participantes do presente estudo (39\%), tem sido também foi positivamente associado a níveis superiores de atividades física em crianças inglesas ${ }^{52}$. A utilização de bicicletas e caminhada até a escola das crianças investigadas pode ser um fator protetivo da saúde contribuindo para os níveis de atividade física diário dessas crianças.

Quanto aos outros aspectos investigados no presente estudo, como os espaços destinados as brincadeiras, o tipo de atividade praticada dentro e fora do lar, os quais também são fatores importantes na rotina de atividades das criança, os mesmos não sofreram modificações significativas. Destaca-se tais aspectos não dependem somente da crianças, mas também da logística familiar e dos espaços e objetos disponíveis no ambiente em que a criança está inserida, não sendo aspectos tão fáceis para serem modificados, apesar de importantes par ao desenvolvimento infantil. Por exemplo, em relação aos espaços destinados as brincadeiras, um dado preocupante chama atenção: quatro crianças do grupo interventivo e três do grupo controle relataram brincar apenas dentro de casa ou do apartamento, espaço esse bastante limitado especialmente para a realização de atividades de ampla movimentação.

As mudanças sociais e os crescentes hábitos sedentários da população devido à dificuldade de mobilidade em cidades em decorrência do tráfego urbano, o crescente envolvimento em jogos eletrônicos, a implementação de rotinas excessivamente organizadas e controladas provocam restrição dos espaços disponíveis para as brincadeiras na rua ${ }^{54}$, característica de gerações passadas A exploração dos espaços, as experiências em grupo e os jogos espontâneos tem sido progressivamente diminuído nas últimas gerações.

Além disso, o espaço físico utilizado para as crianças brincarem não são facilmente modificáveis. Por exemplo, os locais em que as crianças brincam dependem da rotina de trabalho dos pais; por exemplo, pais que trabalham o dia todo dificilmente conseguirão levar as crianças sistematicamente para brincar na rua, resultando em maior tempo de permanecia em espaços da moradia. Estudos prévios sugerem que somente $5 \%$ das crianças brincam em parques $^{50}$; que somente $10 \%$ a $18 \%$ de crianças brincavam nas ruas ${ }^{50,54}$. Fica evidente que o hábito de brincar na rua ou em parques não faz parte da rotina diária da grande maioria das crianças participantes do presente estudo e das pesquisas apresentadas. A rua deveria ser um espaço de encontro e descobertas entretanto esta está deixando de ser um espaço de interação e convivência entre as crianças e progressivamente tem desaparecido como espaço para a cultura lúdica infantil combinado a autonomia e independência da criança ${ }^{55}$. Pais também inibem os filhos de brincar e se deslocar independentemente nas ruas e parques de cidades em decorrência da falta de segurança nas grandes cidades.

Portanto, a crescente diminuição da liberdade e autonomia para o brincar vai dando lugar aos programas esportivos orientados ${ }^{55,56}$, o que ressalta ainda mais a necessidade do acesso a programas como o implementado no presente estudo par populaçôes de menor poder aquisitivo. Muitas vezes são esses programas são os únicos espaços em que crianças vivenciam momentos de instrução efetiva e de autonomia e de prática de atividades amplas que possam contribuir para sua qualidade de vida. Este pressuposto é reforçado quando observa-se ainda que as atividades praticadas dentro do lar, com grandes períodos assistindo televisão foi presente nas rotinas das crianças participantes. 
No presente estudo, considerando que os participantes dispõem de aproximadamente três horas para brincar, e que durante esse tempo permanecem em torno de duas horas assistindo à televisão ou vídeos em seu tempo livre, similar aos resultados reportados por BERLEZE E HAEFFNER ${ }^{50}$, Neto et al..$^{54}$ e Matsudo et al. ${ }^{19}$ a consequência desta rotina é preocupante. $\mathrm{O}$ hábito de assistir à televisão pode levar à participação reduzida em atividades com maior movimentação ${ }^{14}$. NETO ${ }^{56}$ destaca que em televisão, videogame, computador e internet levam a uma vida com hábitos mais sedentários e decréscimo na participação em atividades físicas. Esses hábitos prejudicam o desenvolvimento de competências sociais e da autoestima, diminuem os hábitos de leitura e estão relacionados ao aparecimento de comportamentos antissociais, como a agressividade ${ }^{56}$ e escolha por hábitos mais sedentários ${ }^{18}$.

Em relação à frequência de prática das atividades fora do lar, tanto as de locomoção quanto as de manipulação, eram praticadas duas ou três vezes por semana pela maioria dos participantes. Comparando com estudo prévio a frequência de andar de bicicleta, resultado do presente estudo, foi semelhante ao reportado por BERLEZE E HAEFFNER ${ }^{50}$. Entretanto, percentual de participantes que relataram praticar corridas e jogos com bola no estudo de Berleze e HaEFfner ${ }^{50}$ foi ainda menor do que o encontrado no presente estudo. Em geral, no presente estudo, poucas crianças praticavam as atividades de ampla movimentação diariamente, ao contrário do verificado nas atividades de assistir à televisão ou vídeos e utilizar o computador, que são realizadas diariamente. Esta rotina é preocupante principalmente levando-se em conta que os níveis de atividade física de crianças vêm sendo considerados abaixo do indicado para uma vida saudável ${ }^{15}$, especialmente em crianças de famílias com condiçôes socioeconômicas menos favorecidas ${ }^{22}$, nível socioeconômico dos participantes do presente estudo. Apesar de preocupante, esse resultado não é surpreendente, pois atualmente as crianças têm mais oportunidades de se engajar em atividades sedentárias, diminuindo assim o tempo despendido em atividades mais ativas ${ }^{21}$.

Comportamentos sedentários podem comprometer a saúde de crianças e joven ${ }^{57}$, assim como prejudicar o desenvolvimento das habilidades motoras ${ }^{12}$. Crianças mais proficientes motoramente também são mais ativas fisicamente ${ }^{58}$, aumentando a preocupação com os hábitos ativos de vida das crianças da sociedade atual. Na infância as crianças deveriam estar envolvidas em atividades que proporcionassem o desenvolvimento de suas habilidades amplas e de níveis de atividade física de intensidade moderada ou vigorosa, o que não ocorria para nenhuma das crianças do apresente estudo ate o momento de ingresso no programa. Ressaltamos que as atividades praticadas pelas crianças muitas vezes dependem do ambiente disponível para as brincadeiras, o que muitas vezes impossibilita a realização de atividades mais ativas. Por exemplo, crianças que permanecem a maior parte do tempo brincando nas dependências da moradia, muitas vezes não tem espaço adequado para realizar atividades que envolvam motricidade ampla, como correr e jogar bola. Nesse sentido, esse é um aspecto mais difícil de ser modificado apenas pelo envolvimento em um programa esportivo como o do presente estudo, uma vez que não depende apenas mudanças de hábitos da criança mas sim dependem de fatores econômicos familiares.

$\mathrm{Na}$ comparação entre os sexos, não foram verificadas diferenças significativas no desempenho motor no GI na prática em atividades infantis entre meninas e meninos do GI e GC. Somente no desempenho motor do grupo controle, os meninos demonstraram maior proficiência em HCO. Portanto, os resultados encontrados contrariam em parte a hipótese estabelecida de que meninos vivenciariam escores mais elevados de desempenho motor e mais oportunidades de prática motora no ambiente familiar quando comparados às meninas. Observa-se uma tendência da sociedade a propiciar mais oportunidades de práticas ampla e vigorosa para os meninos em virtude de fatores socioculturais o que não foi observado no presente estudo ${ }^{50-61}$, as famílias propiciavam atividades semelhantes tanto no GI como no GC. Embora a literatura ${ }^{62}$ destaque $^{2}$ que esse direcionamento desde tão cedo faz com que a maioria das crianças já tenha estabelecido a preferência por atividades direcionadas aos diferentes sexos por volta dos três anos de idade. Essa tendência não foi confirmada no presente estudo, de forma que as meninas e os meninos dessa pesquisa parecem estar vivenciando oportunidades semelhantes de prática motora. Embora, os meninos do GC tenham reportado escores motores mais elevados nas $\mathrm{HCO}$, os quais podem ser decorrentes de outras oportunidades que vivenciam em outros contextos de desenvolvimento que não a família, este resultado não foi observado para o GI. Estudos prévios ${ }^{6,38,40,63}$ reforçam o que foi observado no GC, ou seja semelhança nas habilidades de locomoção 
entre meninos e meninas e escores superiores para meninos nas habilidade de controle de objeto.

O programa teve impacto semelhante no desempenho motor e impacto parcial na rotina de atividades infantis de meninos e meninas, demonstrando que os benefícios da participação em atividades esportivas podem ir além do desenvolvimento de habilidades especializadas. Algumas mudanças na rotina dos participantes não foram observadas, em geral, em oportunidades que requerem alterações na rotina do ambiente familiar, fator este que não dependa da criança e sim da logística e de fatores socioeconômicos das famílias participantes.

Concluindo, programas de iniciação esportivas com propostas adequadas ao desenvolvimento e com o emprego de estratégias motivacionais e procedimentos adequados são capazes de suprir as necessidades dos participantes, potencializando o desenvolvimento motor de crianças. A proficiência motora além de garantir a participação nos jogos e brincadeiras infantis pode ainda contribuir para que os participantes tornem-se adolescentes e adultos engajados na prática de atividades recreativas, esportivas e sociais. Considerando a importância de uma vida ativa, é investigando a validade de programas sociais, que podemos também contribuir para práticas pedagógicas mais efetivas na mudança de um quadro de atrasos motores observados no Brasil e com o descaso com a importância da atividade física na infância. Entretanto destaca-se que torna-se essencial a continuidade da pesquisa para que seja avaliado se as mudanças advindas da participação no programa investigado foram permanentes. Ressaltamos a necessidade de mais estudos que investiguem o impacto da participação em programas de iniciação esportiva na rotina diária de atividades das crianças.

\title{
Agradecimentos
}

Agradecemos o apoio do CNPQ e da Capes para a presente pesquisa através da concessão de bolsas de estudo.

\section{Conflito de interesse}

Não há conflitos de interesse.

\begin{abstract}
The influence of youth sport program in the motor development and in the routine activities of children

The opportunities offered to children in different development contexts play a fundamental role in the motor outcome as well as in the life habits of the child. A diversified motor base is important so that the child can successfully enter into sports activities throughout adolescence. The objective of this study was to investigate the effect of the insertion of a sports initiation program on the motor performance and routine of children's activities. Test of Gross Motor Development-Second Edition and an adapted questionnaire about routine childhood activities were used in the present study. The children were paired and distributed in control and interventional groups. The intervention group participated in a sports initiation program, lasting 35 weeks and 56 days of classes. The children in the intervention group attended the program twice a week and the classes were implemented with the mood of motivation for mastery. The children in the control group attended regular physical education classes twice a week. The results indicated: (1) positive and significant changes from pre-post-intervention to motor quotient, locomotor skills and object control in the group of children who participated in the intervention program; (2) upper motor scores in the post-test for the intervention group; (3) positive changes in the daily activity routine of the intervention group; and (4) negative changes in the daily activity routine in the control group. Participation in sports programs
\end{abstract}


results in increased motor proficiency and more movement-oriented routines in children.

Kerwords: Intervention Studies; Child Development; Compensatory Programs; Child; Proficiency Motor.

\section{Referências}

1. Gallahue D, Ozmun JC. Compreendendo o desenvolvimento motor: bebês, crianças, adolescentes e adultos. São Paulo: Phorte; 2005.

2. Haywood KM, Getchell N. Desenvolvimento motor ao longo da vida. Porto Alegre: Artmed; 2010.

3. Gabbard CP. Lifelong motor development. Boston: Allyn and Bacon; 2000.

4. Berleze A, Haeffner LSB, Valentini NC. Desempenho motor de crianças obesas: uma investigação do processo e produto das habilidades motoras fundamentais. Rev Bras Cineantropom Desempenho Hum. 2007;9(2):134-144.

5. Braga RK, Krebs RJ, Valentini NC, Tkac C. A influência de um programa de intervenção motora no desempenho das habilidades locomotoras de crianças com idade entre 6 e 7 anos. Rev Educ Fís/UEM. 2009;20:171-181.

6. Brauner LM, Valentini NC. Análise do desempenho motor de crianças participantes de um programa de atividades físicas. Rev Educ Física/UEM [Internet]. 2009 [citado 2013 Ago 8];20(2):205-16. Disponível em: http://periodicos. uem.br/ojs/index.php/RevEducFis/article/view/6070.

7. Palma MS, Pereira B, Valentini NC. O desenvolvimento motor de pré-escolares com diferentes níveis iniciais de habilidade. In: Rodrigues LP, Saraiva L, Barreiros J, Vasconcelos O, organizadores. Estudos em Desenvolvimento Motor da Criança II. Viana do Castelo: Escola Superior de Educação do Instituto Politécnico de Viana do Castelo; 2009. p.207-215.

8. Villwock G, Valentini NC. Percepção de competência atlética, orientação motivacional e competência motora em crianças de escolas públicas: estudo desenvolvimentista e correlacional. Rev Paul Educ Fís. 2007;21:245-257.

9. Bronfenbrenner $\mathrm{U}$. The bioecological theory of human developmental. In: Bronfenbrenner U, editor. Making Human Beings Human: Bioecological Perspectives on Human Development. Thousand Oaks: Sage Publications; 2001. p.3-15.

10. Krebs RJ, Copetti F, Beltrame TS. Crescimento e atividade física na infância: uma abordagem a partir da teoria dos sistemas ecológicos. Cinergis. 2000;1(2):37-50.

11. Krebs RJ. O jogo infantil e teoria dos sistemas dinâmicos. In: Krebs RJ, Neto C, editors. Tópicos em desenvolvimento motor na infância e adolescência. Rio de Janeiro: LECSU; 2007. p. 105-19.

12. Bronfenbrenner U. A ecologia do desenvolvimento humano: experimentos naturais e planejados. Porto Alegre: Artmed; 1996.

13. Stodden DF, Goodway JD, Langendorfer SJ, Roberton MA, Rudisill ME, Garcia C, et al. A Developmental Perspective on the Role of Motor Skill Competence in Physical Activity: An Emergent Relationship. Quest. 2008;60(2):290-306.

14. Payne GV, Isaacs LD. Desenvolvimento motor humano: uma abordagem vitalícia. São Paulo: Guanabara Koogan; 2007.

15. Papalia DE, Olds SW, Feldman RD. A ciência do desenvolvimento humano. Porto Alegre: AMGH; 2006.

16. Barros SSH, da Silva Lopes A, de Barros MVG. Prevalência de baixo nivel de atividade física em crianças pré-escolares. Rev Bras Cineantropom Desempenho Hum. 2012;14(4):390-400.

17. Neto C. A motricidade como expressão do desenvolvimento da criança: algumas notas históricas e pedagógicas. In: UDESCE da, editor. Desenvolvimento Infantil em Contexto: Livro Anual da Sociedade Internacional para Estudos da Criança. Florianópolis: [editora desconhecida]; 2001. p. 81-99.

18. Seabra AFT, Mendonça DM de MV de, Garganta RM, Maia JAR. Influence of demographic-biological and socialcultural determinants in the levels of physical activity in children and youngsters. Brazilian J Kinanthropometry Hum Perform. 2006;6(2):62-72.

19. Matsudo VKR, Andrade DR, Matsudo SMM, Araújo TL, Andrade E, et al. "Construindo” saúde por meio da atividade física. R Bras Ci e Mov. 2003;11(4):111-118.

20. Machado H dos S, Campos W de, Silva SG da. Relação entre composição corporal e a performance de padróes motores fundamentais em escolares. Rev Bras Atividade Física Saúde. 2002;7(1):63-70.

21. Salmon J, Ball K, Crawford D, Booth M, Telford A, Hume C, et al. Reducing sedentary behaviour and increasing physical activity among 10-year-old children: overview and process evaluation of the "Switch-Play" intervention. Health 
Promot Int. 2005;20(1):7-17.

22. Lindquist CH, Reynolds KD, Goran MI. Sociocultural determinants of physical activity among children. Prev Med (Baltim). 1999;29(4):305-12.

23. Cooper AR, Andersen LB, Wedderkopp N, Page AS, Froberg K. Physical activity levels of children who walk, cycle, or are driven to school. Am J Prev Med. 2005;29(3):179-84.

24. Tucker P. The physical activity levels of preschool-aged children: A systematic review. Early Child Res Q. 2008;23(4):54758.

25. Valentini NC, Rudisill ME. Motivational climate, motor-skill development and perceived competence: two studies of developmental delayed kindergarten children. J Teach Phys Educ. 2004;23:216-234.

26. Valentini NC. A influência de uma intervenção motora no desempenho motor e na percepção de competência de crianças com atrasos motores. Rev Paul Educ Fís. 2002;16(1):61-75.

27. Thomas JR, Nelson JK, Silverman SJ. Métodos de pesquisa em atividade física. Porto Alegre: Artmed; 2012.

28. Ulrich DA. The test of gross motor development - second edition. Austin: Pro-Ed; 2000.

29. Valentini NC. Validity and reliability of the TGMD-2 for Brazilian children. J Motor Behav. 2012;44:275-280.

30. Serrano J, Neto C. As rotinas de vida diária das crianças com idades compreendidas entre os 7 e os 10 anos nos meios rural e urbano. In: Jogo \& Desenvolvimento da criança. Lisboa: Ediçôes FMH; 1997. p. 206-25.

31. Berleze A. Desenvolvimento motor de crianças obesas: uma análise de contexto [dissertação]. Santa Maria: Universidade Federal de Santa Maria; 2002.

32. Delors J, Al-Mufti I, Amagi I, Carneiro R, Chung F, Geremek B, et al. Educação: um tesouro a descobrir. Relatório para a UNESCO da Comissão Internacional sobre Educação para o Séc. XXI. Ediçôes U, editor. ... Unesco da Comissão Internacional sobre Educação .... São Paulo: Cortez Editora; 1998. 288 p.

33. Ames C. Achievement goals, motivational climate, and motivational processes. In: Roberts GC, editor. Motivation in sport and exercise. Champaign: Human Kinetics Books; 1995. p.161-176.

34. Valentini NC, Rudisill ME, Goodway JD. Mastery Climate: Children in Charge of their own learning. Teach Elem Phys Educ. 1999;10:6-10.

35. Valentini NC, Rudisill ME, Goodway JD. Incorporating a mastery climate into elementary physical education: it's developmentally appropriate! JOPERD. 1999;70(7):28-32.

36. Píffero CM, Valentini NC. Habilidades Especializadas do Tênis: Um estudo de intervenção na iniciação esportiva com crianças escolares. Rev Bras Educ Fís Esporte. 2010;24:149-163.

37. Goodway JD, Crowe H, Ward P. Effects of motor skill instruction on fundamental motor skill development. Adapt Phys Act Q. 2003;20:298-314.

38. Valentini NC. Percepçôes de competência e desenvolvimento motor de meninos e meninas: um estudo transversal. Revista Movimento. 2002;8(2):51-62.

39. Valentini NC, Rudisill ME. An inclusive mastery climate intervention and the motor skill development of children with and without disabilities. Adapt Phys Act Q. 2004;21(4):330-347.

40. Goodway JD, Robinson LE, Crowe H. Gender differences in fundamental motor skill development in disadvantaged preschoolers from two geographical regions. Res Q Exerc Sport. 2010;81(1):17-25.

41. Valentini NC, Rudisill ME, Goodway JD. Mastery climate: children in charge of their own learning. TEPE. 1999;10:610.

42. Clark JE, Metcalfe JS. The mountain of motor development: a metaphor. In: Clark JE, Humphrey J, organizadores. Motor development: research and reviews. Reston: NASPE; 2002. 2 vol. p.163-190.

43. Valentini NC, Rudisill ME. An inclusive mastery climate intervention and the motor skill development of children with and without disabilities. Adapt Phys Act Q. 2004;21(4):330-347.

44. Palma MS, Pereira BO, Valentini NC. Guided play and free play in an enriched environment: Impact on motor development. Motriz: rev educ fís. 2014;20:177-185.

45. Springer AE, Kelder SH, Hoelscher DM. Social support, physical activity and sedentary behavior among 6th-grade girls: A cross-sectional study. Int J Behav Nutr Phys Act. 2006;10:1-10.

46. Sawka KJ, McCormack GR, Nettel-Aguirre A, Blackstaffe A, Perry R, Hawe P. Associations between Aspects of Friendship Networks, Physical Activity, and Sedentary Behaviour among Adolescents. J Obes. 2014;2014:1-12.

47. Beets MW, Voge R, Forlaw L, Pitetti KH, Cardinal BJ. Social support and youth physical activity: the role of provider and type. Am J Health Behav. 2006;30(3):278-89.

48. Lemos N de, Nakamura PM, Grisi RN de F, Kokubun E. Associação entre nível de atividade física de lazer dos pais 
com o nível de atividade física dos fi lhos. Rev Bras Atividade Física e Saúde. 2010;15(2):95-100.

49. Fernandes RA, Christofaro DGD, Milanez VF, Casonatto J, Cardoso JR, Ronque ERV, et al. Atividade física: Prevalência, fatores relacionados e associação entre pais e filhos. Rev Paul Pediatr. 2011;29(1):54-9.

50. Berleze A, Haeffner LSB. Rotina de atividades infantis de crianças obesas nos contextos familiar e escolar. Cinergis2. 2002;3(2):99-110.

51. Malho MJ. A Criança e a Cidade: Independência de Mobilidade e Representaçóes sobre o Espaço Urbano. Actas dos ateliers do V congresso português de sociologia. 2004;5:49-56.

52. Cooper AR, Page AS, Foster LJ, Qahwaji D. Commuting to school: Are Children Who Walk More Physically Active? Am J Prev Med. 2003;25(4):273-6.

53. Sirard JR, Slater ME. Walking and bicycling to school: a review. Am J Lifestyle Med. 2008;2(5):372-96.

54. Neto AS, Mascarenhas LPG, Nunes GF, Lepre C, Campos W de. Relação entre fatores ambientais e habilidades motoras básicas em crianças de 6 e 7 anos. Rev Mackenzie Educ Física e Esporte. 2004;3(3):135-40.

55. Neto C, Malho MJ. Espaço urbano e a independência de mobilidade na infância. Bol do IAC. 2004;1-4.

56. Neto C. O jogo e o tempo livre nas rotinas de vida quotidiana de crianças e jovens. Lisboa: Universidade Técnica de Lisboa, Faculdade de Motricidade Humana; 1999. p. 11-21.

57. Gavarry O, Giacomoni M, Bernard T, Seymat M, Falgairette G. Habitual physical activity in children and adolescents during school and free days. Med Sci Sport Exerc. 2003;35(3):525-31.

58. Spessato BC, Gabbard C, Valentini NC. The Role of Motor Competence and Body Mass Index in Children 's Activity Levels in Physical Education Classes. J Teach Phys Educ. 2013;32:118-30.

59. Valentini NC. Percepçóes de Competência e Desenvolvimento Motor de meninos e meninas : um estudo transversal_b. Movimento. 2002;8(2):51-62.

60. Spessato BC, Gabbard C, Valentini N, Rudisill M. Gender differences in Brazilian children's fundamental movement skill performance. Early Child Dev Care. 2013;183(7):916-23.

61. Almeida G de, Valentini NC, Berleze A. Percepçóes de Competência : Um Estudo com Crianças e Adolescentes do Ensino Fundamental. Movimento. 2009;15(1):71-97.

62. Gabbard CP. Lifelong motor development. Boston: Allyn and Bacon; 2000.

63. Valentini NC, Coutinho MTC, Pansera SM, Santos VPA, Vieira JLL, Ramalho MHS, et al. Prevalência de déficits motores e desordem coordenativa desenvolvimental em crianças da região Sul do Brasil. Rev Paul Pediatr. 2012;30(3):377-384.

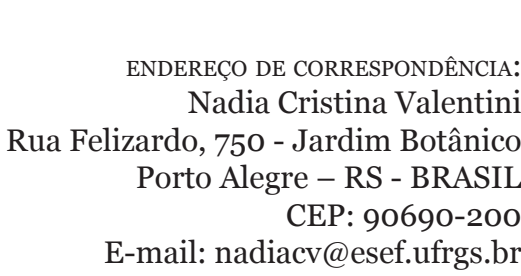

E-mail: nadiacv@esef.ufrgs.br
Submetido: 08/01/2016

$1^{\text {a }}$ revisão: 01/09/2017

$2^{\text {a }}$ revisão: $13 / 12 / 2017$

Aceito: 09/04/2018 